\title{
Evidence of predation/scavenging on Moschidae (Mammalia, Ruminantia) from the Late Miocene of Spain
}

\author{
MARÍA SOLEDAD DOMINGO, ISRAEL M. SÁNCHEZ, MARÍA TERESA ALBERDI, BEATRIZ AZANZA AND \\ JORGE MORALES
}

LETHAIA

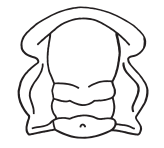
Domingo, M.S., Sánchez, I.M., Alberdi, M.T., Azanza, B. \& Morales, J. 2011: Evidence of
predation/scavenging on Moschidae (Mammalia, Ruminantia) from the Late Miocene
of Spain. Lethaia, Vol. 45, pp. 386-400.

\begin{abstract}
Fossil remains belonging to three musk deer species (Moschidae) from the Late Miocene pseudo-karstic fossil site of Batallones-1 (Madrid, Spain) bear evidence of corrosion produced by digestive acids. Although moschid bones co-occur with remains of several other vertebrate taxa, modifications due to digestion are restricted to the fossils of these ruminants. In this study, we focus on the particular taphonomic history undergone by the moschid assemblage. A description of the bone-surface modifications together with an analysis of the skeletal part representation and bone breakage are provided. The absence in the fossil site of many moschid skeletal elements and fragments of long bones indicates that these ruminants were preyed on or consumed out of the cavity and eventually became part of the bone assemblage when their predator/scavenger became trapped. The features exhibited by the moschid fossiliferous assemblage allow the evaluation of the trophic interactions in this Late Miocene community. The ailurid Simocyon batalleri and the amphicyonid Magericyon anceps are potentially responsible for the moschid assemblage considering the taphonomical features exhibited by the musk deer remains (type and degree of digestive damage and bone breakage, size of the recovered remains) and the dietary adaptations and preferences of these carnivorans. Together, digestive corrosion traces and moschid bone assemblage characteristics provide strong evidence for specific predator-prey interactions in a Miocene ecosystem. Batallones-1, digestion, Miocene, Moschidae, taphonomy.
\end{abstract}

Maria Soledad Domingo [soledm@umich.edu], Museum of Paleontology, University of Michigan, 1109 Geddes Avenue, Ann Arbor, MI 48109, USA; Israel M. Sánchez [israelms@mncn.csic.es], María Teresa Alberdi [mcnaa3j@mncn.csic.es] and Jorge Morales [mcnm166@mncn.csic.es], Departamento de Paleobiología, Museo Nacional de Ciencias Naturales-CSIC, C/José Gutiérrez Abascal, 2, 28006, Madrid, Spain; Beatriz Azanza [azanza@unizar.es], Departamento de Ciencias de la Tierra, Facultad Ciencias, Universidad de Zaragoza, C/Pedro Cerbuna, 12, 50009, Zaragoza, Spain; manuscript received on 06/06/2011; manuscript accepted on 08/09/2011.
The fossil sites of Cerro de los Batallones (Madrid Basin, Spain) are characterized by the abundant and diverse mammalian remains of Vallesian age (late Miocene) recovered from them (Fig. 1). The high volume of fossil material and its good preservation have enhanced our knowledge of Miocene herbivore and carnivore mammalian species poorly known so far (Morales et al. 1992, 2008; Cerdeño \& Sánchez 1998; Antón et al. 2004a; Peigné et al. 2005, 2008; Salesa et al. 2005, 2006a,b, 2008, 2009; Sánchez et al. 2009; López-Antoñanzas et al. 2010). Recently, one of us (MSD) conducted the first comprehensive taphonomic analysis of one of these localities, the fossil site of Batallones-1 (Domingo 2009). The advantage provided by a detailed taphonomic analysis lies in that it allows the detection of singular taphonomic histories for some of the remains and/or taxa relative to the general formation mode of a fossil site. As such, this work arises as a consequence of the identification of distinctive bone surface modifications almost exclusively present in fossil bones from a particular mammalian clade: the Moschidae. Moschids (musk deer) are a clade of small hornless pecoran ruminants whose only extant representative is the Asian musk deer, Moschus spp. (Nowak 1999; Sánchez et al. 2010). The Moschidae comprise Micromeryx, Hispanomeryx, Moschus, 'Moschus' grandeavus, their last common ancestor and all of its descendants (Sánchez et al. 2010).

The bone alteration exhibited by the moschid remains studied is distinctive, typifying the digestion process. There is a large body of actualistic studies on the characterization of the effects of ingestion and digestion of bone produced by different predators including raptors and other birds, mammalian carnivores (counting humans and other primates), and crocodiles (Sutcliffe 1970; Mellet 1974; Dodson \& Wexlar 1979; Fisher 1981; Andrews \& Evans 1983; Andrews 1990; Schmitt \& Juell 1994; Crandall \& Stahl 

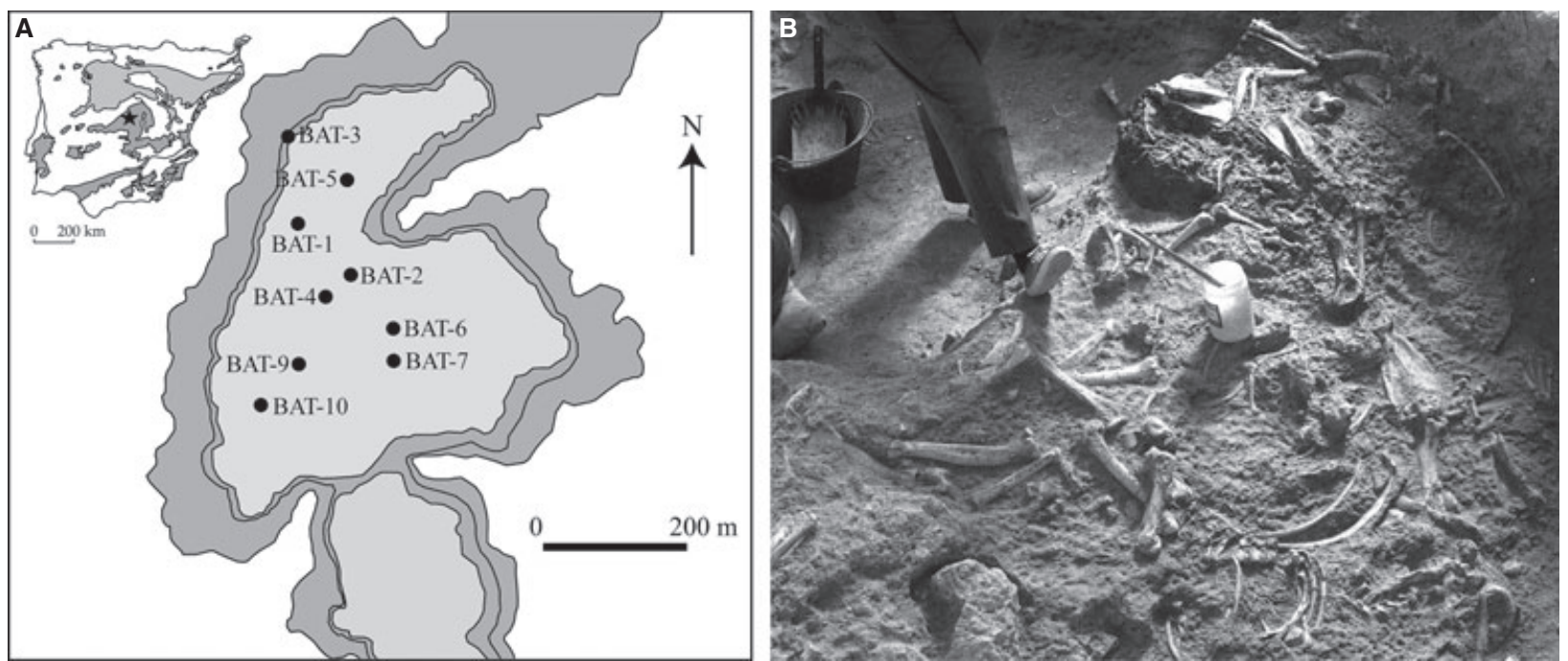

Fig. 1. A, Cerro de los Batallones aerial sketch with the location of the fossil sites (modified from Pozo et al. 2004). The black star in the map of the Cenozoic basins of the Iberian Peninsula (in grey in the upper left hand corner) shows the location of the Madrid Basin, where Cerro de los Batallones is situated. BAT-1, Batallones-1, BAT-2, Batallones-2, BAT-3, Batallones-3, and so forth. B, bone concentration from the lower level assemblage of Batallones-1. Note that most of the long bones are complete.

1995; Hockett 1996; Stewart et al. 1999; Tappen \& Wrangham 2000; Robert \& Vigne 2002; Pickering \& Carlson 2004; Laudet \& Selva 2005; Trapani et al. 2006; Montalvo et al. 2007; Lloveras et al. 2008; Esteban-Nadal et al. 2010). Accordingly, general modifications caused by this process are relatively well known and have also been detected in accumulations from the past (Andrews 1990; Andrews \& Ersoy 1990; Fernández-Jalvo \& Andrews 1992; Fernández-Jalvo et al. 1998; Stewart et al. 1999; Sanz et al. 2001; Varricchio 2001; Robert \& Vigne 2002; Marín Arroyo et al. 2009; Farlow et al. 2010). Most of these works refer to small mammal remains (orders Rodentia, Insectivora and Lagomorpha) because they are usually prey of a wider spectrum of predators than large mammals and their skeletal elements commonly remain identifiable in the faeces and pellets. Due to their small size, it is not unusual for moschid bones to be easily swallowed while still remaining recognizable, as is shown in this study.

Most studies dealing with the accumulation of fossil bones with evidence of digestion try to elucidate the predator/scavenger responsible for the ingestion of the remains. To do this, not only the type of bone surface alteration produced by the digestive acids is described but also the completeness of the skeletal parts and the breakage pattern are evaluated since each predator seems to yield specific results. However, the proposal of feasible candidates for the origination of a digested assemblage becomes more difficult as we go deeper in time because the carnivore fauna lack modern comparable taxa.

The aim of this work was to describe features indicative of the digestion process undergone by the moschid remains from Batallones- 1 and also to carry out analyses of fragmentation and completeness of the sample. Where possible, comparisons of the taphonomic attributes exhibited by the musk deer assemblage and the rest of the mammalian assemblage were also carried out. Based on the characterization of the moschid material, the particular taphonomic history of the accumulation of these ruminants is delineated and the trophic interactions between the moschids and different predators/scavengers examined. This study constitutes a contribution to the very few works that describe modification due to digestion in identifiable mammalian remains other than small mammal remains and provide evidence of direct predator-prey relationships in a Miocene community.

\section{Geological setting and background}

Cerro de los Batallones is a structural butte located in the Madrid Basin. It comprises nine fossil sites composed mainly of mammalian fossil remains (Fig. 1). The faunal content yields a Vallesian age (local zone J, MN10, ca. 9 Ma; early Late Miocene) for all the sites. A characteristic feature of these localities is that the fossiliferous concentrations are embedded in a sedimentary matrix that discordantly cuts the stratigraphical sequence of the butte. Based on this feature and on geophysical surveys, Pozo et al. (2004) proposed that Cerro de los Batallones remains were deposited in cavities with an upper opening formed as the result of the subsurficial hydraulic erosion of clayey sediments (this pseudo-karstic process is known as piping). The 
sedimentary matrix of the fossil sites consist of olive marls and fine to coarse siliciclastics that correspond to the infilling of the cavities due to episodic floods (see Pozo et al. 2004 and Domingo et al. 2011 for further geological information).

Batallones- 1 consists of two successive fossiliferous assemblages separated by a unit of identical lithology, but practically sterile in fossils. The lower level assemblage (LLA) is dominated by carnivoran remains (\%NISP (= number of identified specimens per taxon) carnivorans in Batallones-1 LLA $=98.32 \%$ ) whilst the upper assemblage (ULA) mainly consists of mammalian herbivore remains (\%NISP herbivores in Batallones-1 ULA $=80.55 \%$ ) (Morales et al. 2008).

All of the moschid remains from Batallones-1 have been found in the LLA. The LLA is interpreted as the deepest part of the cavity. The taxonomic composition of this accumulation and the age profiles of the most abundant taxa - all of them mammalian carnivorans - lead us to suggest that most of the individuals entered the cavity intentionally searching for water or food and, then, they were unable to make their way out (Domingo 2009).

Fossils from Batallones-1 LLA usually exhibit a good preservation state with almost complete absence of modifications due to weathering, transport, trampling, roots, carnivores or rodents. Nevertheless, during the taphonomic evaluation of this assemblage, 22 specimens displaying modifications typically ascribed to the digestion process were found. They account for less than $1 \%$ of the examined sample but, as previously mentioned, they show the particularity that most of these remains (NISP $=18$ ) belong to the Moschidae family. This sample is studied in depth in the present work but preliminary descriptions of the alterations caused by the digestive juices on Batallones-1 LLA moschid remains can be found in Domingo et al. (2007) and Sánchez et al. (2009).

\section{Moschids from Cerro de los Batallones fossil sites}

The Spanish fossil record of the Moschidae spans a time range of 7.5 million years from the MN5 (local zone D; Middle Aragonian; Middle Miocene) to the MN11 (local zone K; Turolian; Late Miocene) (Sánchez \& Morales 2006). Miocene moschids are represented by the genera Micromeryx (Fig. 2) and Hispanomeryx with five and three described species respectively (Vislobokova 2007; Sánchez \& Morales 2008; Sánchez et al. 2009, 2010).

The moschid assemblage from Cerro de los Batallones fossil sites is currently composed of three species Micromeryx soriae, Micromeryx sp. 'large size', and

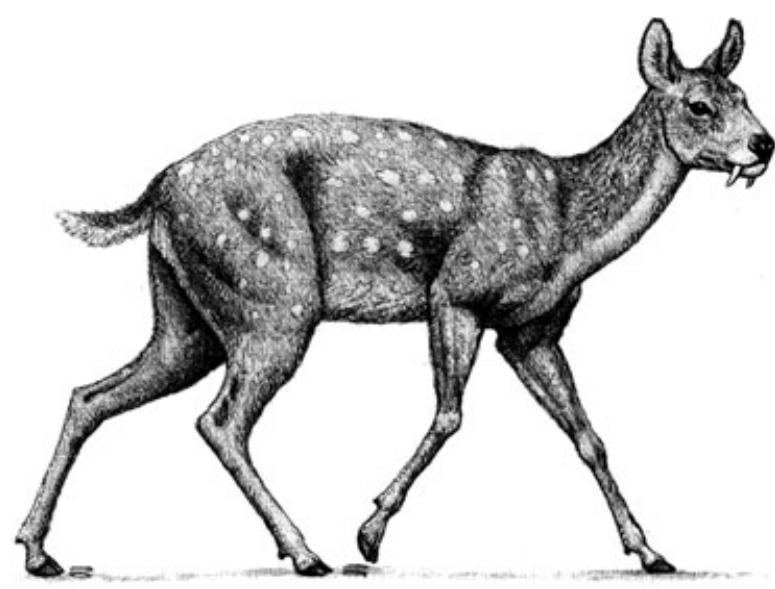

Fig. 2. Reconstructed life appearance of Micromeryx. Art by Mauricio Antón.

Hispanomeryx sp. cf. H. duriensis - all of which are represented in the Batallones-1 LLA. Micromeryx soriae is a medium-sized Micromeryx (around $4.8 \mathrm{~kg}$ ) that was recently erected based on the fossil material from the Vallesian locality of La Roma-2 (Teruel Basin, Spain; Sánchez et al. 2009). Micromeryx sp. 'large size' is, with all probability, the largest moschid taxa (around $8.4 \mathrm{~kg}$ ) of the Spanish Neogene (Sánchez 2006; Sánchez \& Morales 2006). The third moschid, Hispanomeryx sp. cf. H. duriensis, is a medium-sized Hispanomeryx (around $4.9 \mathrm{~kg}$ ), which lacks diagnostic material in the Cerro de los Batallones localities as to unequivocally ascribe it to H. duriensis (Sánchez 2006). Except for Micromeryx sp. 'large size', moschids from Cerro de los Batallones are smaller than modern musk deer whose body mass ranges from 7.5 to $15 \mathrm{~kg}$ (Prikhodko 2003).

\section{Material and methods}

We have analysed a total of 56 specimens (Table 1) that correspond to the entire moschid collection recovered along the whole period of excavation of the LLA of Batallones-1 (1991-93 and 2001-08). These fossils are housed in the collections of the Museo Nacional de Ciencias Naturales-CSIC (Madrid, Spain). All the specimens were examined under a binocular microscope. Those specimens showing evidences of corrosion due to digestion were further examined under an environmental scanning electron microscope (ESEM) FEI Quanta 200 at the Museo Nacional de Ciencias Naturales-CSIC.

Besides NISP, and in order to quantify the skeletal representation of each taxon, the minimum number of elements (MNE) was calculated based on the following attributes: taxon, element, side (right or left), portion of the element recovered, age-class and 
Table 1. Number of identified specimens (NISP), minimum number of elements (MNE), minimum number of individuals (MNI) and relative abundance $\left(\% R_{i}\right)$ of the Moschidae taxa present in Batallones-1 LLA.

\begin{tabular}{lllll}
\hline & NISP & MNE & MNI & $\% R_{i}$ \\
\hline $\begin{array}{l}\text { Micromeryx soriae } \\
\text { Micromeryx sp. 'large size' }\end{array}$ & 19 & 19 & 3 & 4.01 \\
$\begin{array}{l}\text { Hispanomeryx sp. cf. H. duriensis } \\
\text { Moschidae undet. }\end{array}$ & 12 & 11 & 2 & 3.48 \\
Total & 11 & & & \\
\hline
\end{tabular}

association articulation. This calculation follows Badgley (1986) and Lyman (1994) in defining a skeletal element as a single, complete bone or tooth. Two age classes were regarded, adult and juvenile, on the basis of the degree of epiphyseal union to diaphyses and tooth eruption. Minimum number of individuals (MNI) was derived from the most common element for each taxon (Shipman 1981). To investigate bone survivability, relative abundance was calculated using the formula established by Andrews (1990):

$$
R_{i}=\mathrm{MNE}_{i} /\left(\mathrm{MNI} \times E_{i}\right) \times 100
$$

where $R_{i}$ is the relative abundance of element $i, \mathrm{MNE}_{i}$ is the minimum number of element $i$ in the sample, MNI is the minimum number of individuals in the taxon of interest, and $E_{i}$ is the number of times that element $i$ appears in a complete skeleton.

The pattern of fragmentation of the recovered bones can help identifying different predators since some species can swallow their prey whole (e.g. owls), whereas other species chew their prey (e.g. mammalian carnivores) or tear their prey apart (e.g. diurnal birds of prey; Andrews 1990). Consequently, remains have been examined for presence and amount of breakage. Bone breakage was gauged as the percentage of completeness of each identifiable element using the next categories: complete, almost complete (bones only missing some bone chip), more than one-half complete and one-half or less.

Some taphonomic features of the moschid assemblage were statistically compared to the same features exhibited by the rest of the large mammal remains from Batallones-1 LLA. Statistical analysis consisted of the construction of contingency tables that were analysed using chi-square test or the analogous Fisher's exact test when $n<5$ items in any of the compared cells. Significance was established at the $\alpha=0.05$ level.

In our study, under the term 'small mammal/ micromammal' are included the orders Insectivora, Rodentia and Lagomorpha and under the term 'large mammal/macromammal' we include the orders Cetartiodactyla, Perissodactyla, Proboscidea, Primates and Carnivora. Under the term 'long bone' are included humeri, radii, ulnae, femora, tibiae, fibulae and metapodials.

\section{Results}

\section{Taxonomic composition and skeletal representation}

The total number of moschid individuals found in Batallones-1 LLA is six (Table 1). Micromeryx soriae is the most common taxon and is represented by a total of three individuals. There are 11 specimens that cannot be assigned unequivocally to a known moschid taxa because their diagnostic characters are lost or difficult to discern (Tables 1 and 2). The skeletal completeness of the moschid species can be considered as very low with only $4.01 \%$ of bones originally present for Micromeryx soriae, $8.86 \%$ for Micromeryx sp. 'large size', and $3.48 \%$ for Hispanomeryx sp. cf. H. duriensis (Table 1 and Fig. 3). For all taxa, elements from the appendicular skeleton show the highest survivability (NISP $=51 ; 91.07 \%$ of the total sample; Fig. 3 and Table 2) although there are some completely missing bones such as ulnae, femora, fibulae, patellae or calcanei. Cranial elements are very poorly represented (NISP $=5 ; 8.93 \%$ of the total sample) and bones from the axial skeleton are completely absent.

Moschid fossils are too scarce as to allow meaningful and conclusive statistical comparisons of their relative abundances profiles among the moschid species, with other species represented in the Batallones-1 LLA or with recent or fossil digested remains described in other works. Moreover, it must be highlighted that, among the large mammal taxa, only the entire musk deer collection has been examined. On the contrary, the non-moschid large mammal assemblage recovered from Batallones-1 is so extensive that the taphonomic study has been performed only on a subsample of the total unearthed material. Accordingly, and since relative abundance profiles obtained from the non-moschid macro-mammalian taxa cannot be considered as definitive, we refrain from establishing comparisons of the two assemblages. As for a comparison with modern digested remains, most of the studies on scatological accumulations concern micromammal bones with very few works dealing digestion on ruminants or other macromammal taxa; then, again, the comparability of the assemblages does not seem suitable.

\section{Breakage}

Complete bones represent the $39.29 \%$ of the whole moschid assemblage (Fig. 4, Table 3). Micromeryx 
Table 2. Digested and non-digested/unclear skeletal specimens per Moschidae taxon.

\begin{tabular}{|c|c|c|c|c|c|c|c|c|c|}
\hline & \multicolumn{2}{|c|}{ Micromeryx soriae } & \multicolumn{2}{|c|}{ Micromeryx sp. 'large size' } & \multicolumn{2}{|c|}{$\begin{array}{c}\text { Hispanomeryx sp. cf. } H . \\
\text { duriensis }\end{array}$} & \multicolumn{2}{|c|}{ Moschidae undet. } & \multirow[b]{2}{*}{ Total } \\
\hline & Digested & $\begin{array}{l}\text { Without digestion } \\
\text { damage or unclear }\end{array}$ & Digested & $\begin{array}{l}\text { Without digestion } \\
\text { damage or unclear }\end{array}$ & Digested & $\begin{array}{l}\text { Without digestion } \\
\text { damage or unclear }\end{array}$ & Digested & $\begin{array}{l}\text { Without digestion } \\
\text { damage or unclear }\end{array}$ & \\
\hline \multicolumn{10}{|l|}{ Cranial elements } \\
\hline Skull & 0 & 0 & 0 & 0 & 0 & 0 & 0 & 0 & 0 \\
\hline Maxilla & 0 & 0 & 0 & 0 & 0 & 0 & 0 & 0 & 0 \\
\hline Mandible & 0 & 1 & 0 & 0 & 0 & 0 & 0 & 0 & 1 \\
\hline Tooth & 0 & 1 & 0 & 1 & 0 & 0 & 0 & 2 & 4 \\
\hline \multicolumn{10}{|l|}{ Axial skeleton } \\
\hline Vertebra & 0 & 0 & 0 & 0 & 0 & 0 & 0 & 0 & 0 \\
\hline Rib & 0 & 0 & 0 & 0 & 0 & 0 & 0 & 0 & 0 \\
\hline Scapula & 0 & 0 & 0 & 0 & 0 & 0 & 0 & 0 & 0 \\
\hline Pelvis & 0 & 0 & 0 & 0 & 0 & 0 & 0 & 0 & 0 \\
\hline \multicolumn{10}{|c|}{ Appendicular skeleton } \\
\hline Humerus & 0 & 0 & 0 & 0 & $2(1 \mathrm{SF})$ & $1(\mathrm{SF})$ & 0 & 0 & 3 \\
\hline Radius & 0 & 0 & 1 & 0 & $1(\mathrm{SF})$ & $1(\mathrm{SF})$ & 0 & $1(\mathrm{SF})$ & 4 \\
\hline Ulna & 0 & 0 & 0 & 0 & 0 & 0 & 0 & 0 & 0 \\
\hline Femur & 0 & 0 & 0 & 0 & 0 & 0 & 0 & 0 & 0 \\
\hline Tibia & $1(\mathrm{SF})$ & $1(\mathrm{SF})$ & 1 & 1 & 0 & 0 & 0 & 0 & 4 \\
\hline Fibula & 0 & 0 & 0 & 0 & 0 & 0 & 0 & 0 & 0 \\
\hline Patella & 0 & 0 & 0 & 0 & 0 & 0 & 0 & 0 & 0 \\
\hline Carpal & 0 & 2 & 0 & 0 & 2 & 1 & 1 & 0 & 6 \\
\hline Astragalus & 4 & 0 & 1 & 0 & 0 & 0 & 0 & 0 & 5 \\
\hline Calcaneum & 0 & 0 & 0 & 0 & 0 & 0 & 0 & 0 & 0 \\
\hline Other tarsal & 0 & 0 & 0 & 1 & 0 & 1 & 0 & 1 & 3 \\
\hline Metapodial & 0 & 0 & 1 (SF) & 0 & $1(\mathrm{SF})$ & $1(\mathrm{SF})$ & 0 & 3 & 6 \\
\hline Phalanx & 0 & 8 & 0 & 6 & 0 & 1 & 1 & 2 & 18 \\
\hline Malleolus & 1 & 0 & 0 & 1 & 0 & 0 & 0 & 0 & 2 \\
\hline Total & 6 & 13 & 4 & 10 & 6 & 6 & 2 & 9 & 56 \\
\hline
\end{tabular}

SF, long bones exhibiting spiral fractures.

soriae assemblage is mainly composed of dense distal limb elements (carpals, tarsals and phalanges) and, accordingly, it exhibits the highest percentage of complete and nearly complete bones (84.21\%) among the three species. Complete bones in the rest of the taxonomical categories also correspond to these small and dense limb elements.

Extreme levels of fragmentation are observed if only long bones are considered $(100 \%$ of fragmented bones, NISP $=16$, one metapodial excluded as it

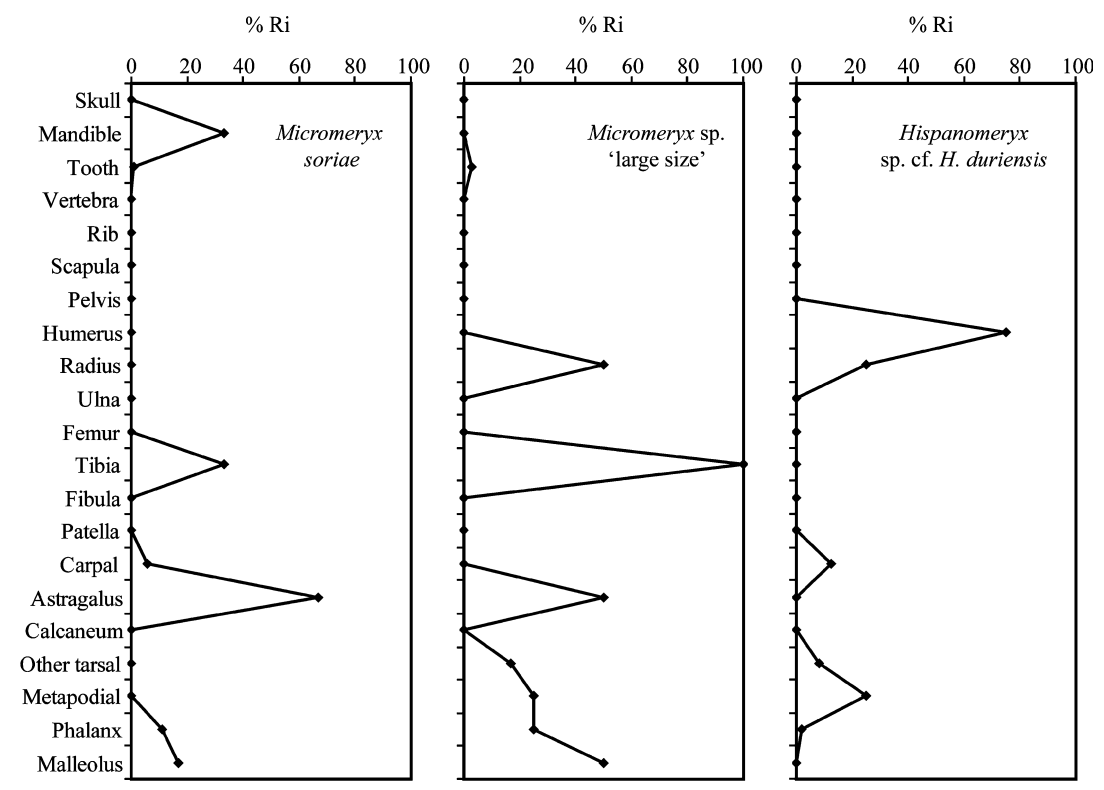

Fig. 3. Skeletal element proportions expressed as relative abundance $\left(\% R_{i}\right)$ of the three Moschidae species from Batallones-1 LLA. 


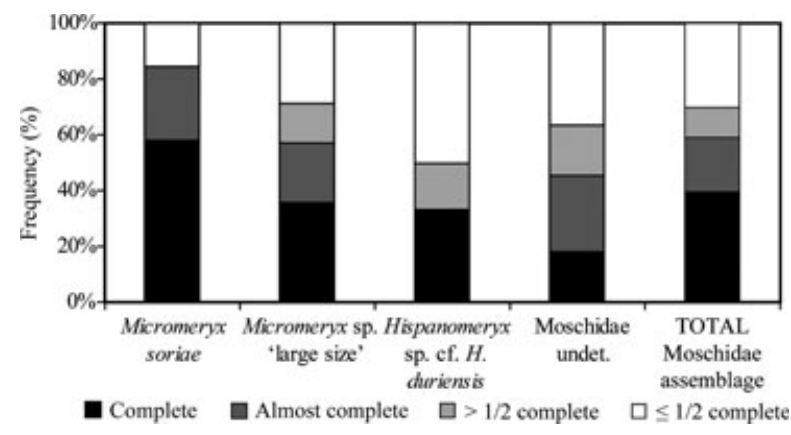

Fig. 4. Percentage breakage of all elements.

corresponds to a disarticulated juvenile distal epiphysis so that it is not considered as a long bone). As such, the higher representation of long bones in the Hispanomeryx sp. cf. H. duriensis assemblage (Table 2) gives rise to the highest percentage of bone breakage among the moschid species (Fig. 4).

The degree of fragmentation of the moschid remains statistically differs from the breakage degree displayed by the rest of fossils evaluated in the Batallones-1 LLA both if total samples are compared or if only long bones are compared. In the two cases, the percentages of fragmentation are higher in the musk deer assemblage (Table 3; note in Fig. 1B that long bones of large mammalian taxa other than moschids are usually preserved complete). Precisely, the higher level of breakage of the moschid total sample compared to the total sample of the rest of the assemblage is partly due to the fact that long bones are proportionally more numerous in the moschid sample and all of them are broken. Spiral fractures predominate in the Moschidae assemblage whereas they are far less numerous in the rest of the evaluated Batallones-1 LLA sample (Tables 2 and 3).

Another distinctive feature of the moschid broken long bones is that, contrary to what observed in the rest of the remains examined in the Batallones-1 LLA, only one of the ends (proximal or distal, and they can include part of the diaphysis) of these elements has been found in the fossil site (except for metapodial B-518, which is fragmented but preserves the two ends).

\section{Bone surface modifications}

Damage on bone surface due to weathering, abrasion, trampling, root action and rodent activity is practically absent in the moschid sample. The same is true for the rest of the Batallones-1 LLA (Table 3). However, as already mentioned, a total of 18 moschid bones (the $32.14 \%$ of the musk deer association) show evidence of corrosion due to the effect of digestion. The incidence of this process on the moschid remains statistically differs from what observed in the rest of the assemblage where only $0.06 \%$ of the bones (all of them splinters) show evident signs of digestion (Table 3 ).

Observed digestion alteration comprises: polishing of the bone surface, rounding of the fracture edges, intrusive digestion that gives as a result the exposure of the spongy bone mainly in the articular areas, and thinning of the bone cortex (Figs 5, 6). All these remains were examined under the ESEM, so we searched for another modification described by

Table 3. Comparison of the taphonomic attributes exhibited by the Batallones-1 LLA Moschidae sample and the rest of the large mammal assemblage. Weathering alteration follows the stages described by Behrensmeyer (1978). Fossil shape follows the approach of Frostick \& Reid (1983).

\begin{tabular}{|c|c|c|c|}
\hline & Moschidae assemblage & Rest of the assemblage & $\begin{array}{l}\text { Chi-square } \\
\text { test/Fisher's } \\
\text { exact test }\end{array}$ \\
\hline Weathering alteration & $1.78 \%$ (Stage 1 or more) & $0.11 \%$ (Stage 1 or more) & ns \\
\hline Trampling marks & $0 \%$ & $0 \%$ & - \\
\hline Root marks & $0 \%$ & $0.06 \%$ & ns \\
\hline Rodent marks & $0 \%$ & $0 \%$ & - \\
\hline \multicolumn{4}{|l|}{ Transport evidences } \\
\hline Abrasion alteration & $0 \%$ & $0.11 \%$ & ns \\
\hline Fossil shape & $\begin{array}{l}\text { Coexistence of rod and } \\
\text { sphere-shaped bones ( } 52.94 \%) \text { and } \\
\text { blade- and disc-shaped bones }(47.06 \%)\end{array}$ & $\begin{array}{l}\text { Coexistence of rod and } \\
\text { sphere-shaped bones }(63.10 \%) \text { and } \\
\text { blade-and disc-shaped bones (36.90\%) }\end{array}$ & ns \\
\hline Digested bones & $32.14 \%$ & $0.06 \%$ & $\mathrm{~s}$ \\
\hline Tooth marks & $0 \%$ & $0.30 \%$ & ns \\
\hline \multicolumn{4}{|l|}{ Fragmentation } \\
\hline Total sample & $60.71 \%$ fragmented & $37.34 \%$ fragmented & $s$ \\
\hline Long bones & $100 \%$ fragmented & $31.08 \%$ fragmented & $\mathrm{s}$ \\
\hline $\begin{array}{l}\text { Broken long bones } \\
\text { exhibiting spiral fracture }\end{array}$ & $62.5 \%$ & $34.27 \%$ & $\mathrm{~s}$ \\
\hline $\begin{array}{l}\text { Compaction and deformation } \\
\text { alteration }\end{array}$ & $3.57 \%$ & $19.32 \%$ & s \\
\hline
\end{tabular}

ns, non-significantly different; s, significantly different $P<0.05$. 
Andrews (1990) that consist in the splitting and cracking of the surfaces very similar to the effect of weathering but only visible at a very fine scale. Some of the bones exhibit marks comparable to this type of modification (Fig. 6J-L).

Some digested bones retain their anatomical connection. These remains consist of skeletal elements from the distal part of the extremities: the left distal epiphysis of a Micromeryx soriae tibia articulated with the malleolus and the astragalus (Fig. 5D) and a right semilunar and scaphoid of a Hispanomeryx cf. sp. $H$. duriensis. The presence of articulated remains is not uncommon in digested assemblages (e.g. Andrews \& Evans 1983; Montalvo et al. 2007; Esteban-Nadal et al. 2010). None of the moschid remains exhibit tooth marks. Tooth marks are practically absent in the rest of the assemblage as well (Table 3). However, in the case of the Moschidae sample, the complete absence of tooth marks may be an artefact produced by the digestive process itself.

All the digested bones belong to the postcranial skeleton. Damage due to digestion is not restricted to a single moschid species but it has been recorded in remains belonging to the three species from Batallones-1 (Table 2). Besides, most of the individuals exhibit bones with modifications due to digestion. The MNI of Micromeryx soriae has been determined from three left astragali, all of them showing damage due to digestive juices. Micromeryx sp. 'large size' is represented by one individual that shows clear modifications due to digestion in four of its remains. Two individuals of Hispanomeryx sp. cf. $H$. duriensis have been estimated from two right humerus distal portions. One of these humeri is clearly digested, whereas the other one furnishes some evidence typical of bones that have been digested such as the exposure of the spongy bone and the thinning of the bone cortical portion. However, it does not exhibit a shiny aspect or rounding of the fracture edges. Therefore, it is probable but not clear that this bone - and this individual underwent digestion.

In this regard, it must be highlighted that we took a conservative approach in the determination of digested bones. Only when most of the previously described modifications were present, a bone was unequivocally identified as a digested bone. However, the lack of digestive corrosion in the remains does not preclude the possibility that they had undergone digestion as well. Different actualistic studies on scat and pellet bone assemblages produced by a varied array of owls, diurnal birds of prey and mammalian carnivores show that not all the remains are affected by the digestive acids (Andrews \& Evans 1983; table 2; Andrews 1990). A feasible explanation for this absence of corrosion is that some protection against digestion was provided by different tissues such as hair, fat, muscle or, even bone when the maxillar and mandible act as a protective cover for the teeth (Andrews \& Evans 1983). Our conservative approach and the possible lack of evidence of digestive corrosion on some of the remains could be leading us to underestimate the number of unidentifiable bones (splinters) that could have actually suffered digestion. In fact, it would be expectable to find a larger sample of unidentified

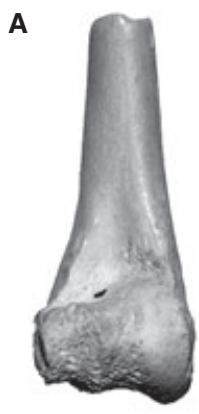

E

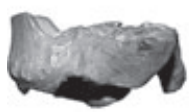

B

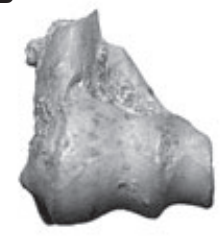

$\mathbf{F}$

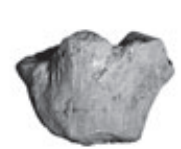

C

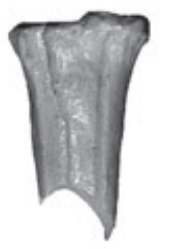

$1 \mathrm{~cm}$

G

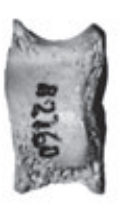

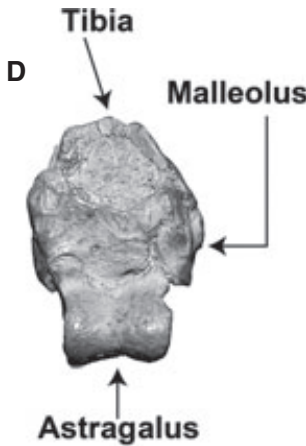

H

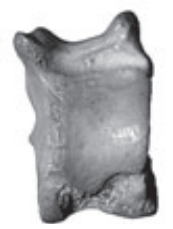

Fig. 5. Moschidae bones showing alterations due to digestion. A, humerus distal diaphysis (B-3223) of Hispanomeryx sp. cf. H. duriensis. B, humerus distal epiphysis (BAT-1'05 F5-153) of Hispanomeryx sp. cf. H. duriensis. C, metacarpal III-IV proximal diaphysis (BAT-1'05 E4185) of Micromeryx sp. 'large size'. D, articulated astragalus, tibia and malleolus (B-4843a, b, and c) of Micromeryx soriae. E, tibia distal epiphysis (B-1756) of Micromeryx sp. 'large size'. F, radius proximal epiphysis (BAT-1'05 F5-211) of Hispanomeryx sp. cf. H. duriensis. G, astragalus (B-2260) of Micromeryx soriae. H, astragalus (B-4058) of Micromeryx sp. 'large size'. Note that bones show a glossy aspect. A, B, C, D, E and F display rounding of the broken edges. A, G and $\mathrm{H}$ exhibit exposure of the spongy bone on the articular surfaces. 

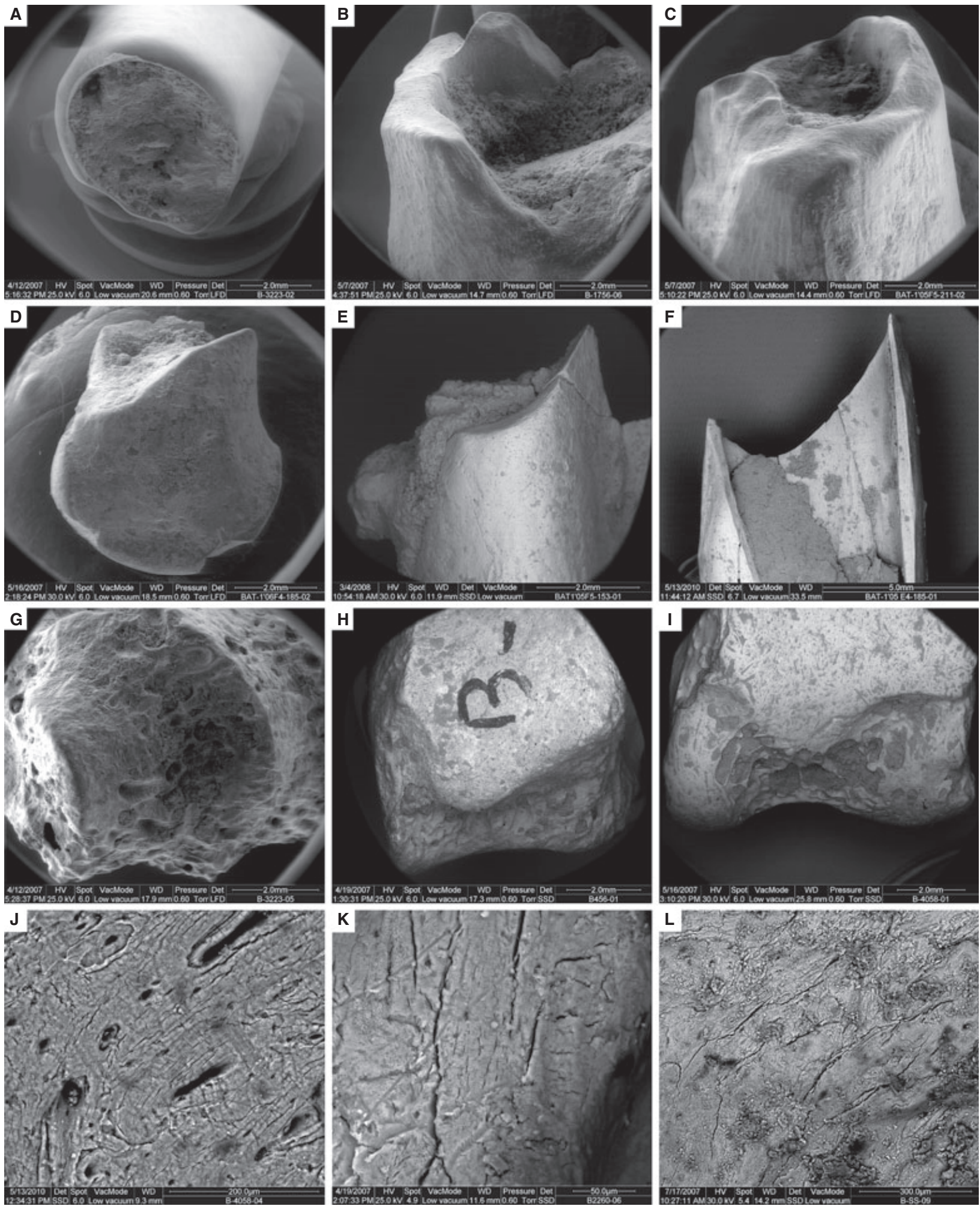

Fig. 6. Environmental scanning electron microscope photographs showing alterations due to digestion in the Moschidae fossils from Batallones-1 LLA. A and G, humerus distal diaphysis (B-3223) of Hispanomeryx sp. cf. H. duriensis. B, tibia distal epiphysis (B-1756) of Micromeryx sp. 'large size'. C, radius proximal epiphysis (BAT-1'05 F5-211) of Hispanomeryx sp. cf. H. duriensis. D, phalanx distal diaphysis (BAT$1^{\prime} 06$ F4-185) of Moschidae undet. E, humerus distal epiphysis (BAT-1'05 F5-153) of Hispanomeryx sp. cf. H. duriensis. F, metacarpal III-IV proximal diaphysis (BAT-1'05 E4-185) of Micromeryx sp. 'large size'. H, astragalus (B-456) of Micromeryx soriae. I and J, astragalus (B-4058) of Micromeryx sp. 'large size'. K, astragalus (B-2260) of Micromeryx soriae. L, astragalus (B-SS) of Micromeryx soriae. A, B, C, D, E and F, broken long bones sporting rounded edges on the fracture surface. Besides, $\mathrm{E}$ and $\mathrm{F}$ display thinning of the cortical portion of the bone. $\mathrm{G}, \mathrm{H}$ and I, exposed spongy bone in the articular portions of the bones. J, K and L, splitting and cracking of bone surfaces. 
fragments of bones among an association of digested remains as shown by different actualistic studies on scatological accumulations (e.g. Andrews \& Evans 1983; Robert \& Vigne 2002; Montalvo et al. 2007; Esteban-Nadal et al. 2010). In these studies, the authors know positively that all the remains have passed through the digestive tract of a predator regardless of the absence of alterations on the bone; that an apparently non-corroded bone has undergone digestion is much more difficult or impossible to assess in accumulations from the past. In their study of the coprogenic sample originated by modern wolves, Esteban-Nadal et al. (2010) observe that the most common modification is the polishing of the bones and, in some cases, this alteration is only incipient. The rest of the modifications are much less frequent. Then, bearing this in mind, it cannot be discarded that the number of digested unidentifiable remains from Batallones-1 LLA would be higher than what we have detected.

\section{Discussion}

\section{Taphonomic causes of moschid bone breakage and survivability}

The bone surface modifications exhibited by the Batallones-1 LLA moschid remains and presented in this study constitute unequivocal evidence that these individuals underwent predatory attacks and/or scavenging of their carcasses and subsequent digestion. Alteration of bone surface due to digestion is virtually absent in the rest of the large mammal sample from Batallones-1 LLA (apart from four splinters of unknown taxonomical adscription; small mammal sample has still not been studied in this respect); therefore, there existed some differing processes in the taphonomic pathway of the moschid remains in comparison with the rest of the accumulation.

Relative abundance and breakage pattern are frequently used as additional lines of evidence leading to determine that a predator/scavenger are responsible for an assemblage containing digested remains. Although the small sample size of the moschid assemblage did not permit statistically comparison of the relative abundance profiles, the degree of breakage of the moschid bones has shown to be high compared to the levels of fragmentation exhibited by the rest of the large mammal remains from Batallones-1 (Table 3). While the corrosive effects of digestion on bones are not duplicated by other taphonomic processes, skeletal representation and fragmentation of remains can be the result of different processes. Then, before using these data, it is important, above all in assemblages from the past, to evaluate the effect of other taphonomic processes on the sample.

It was previously indicated that the great majority of moschid remains do not show bone alteration due to weathering, trampling, root action and rodent activity (Table 3) so these taphonomic processes can be discarded as responsible for the loss of skeletal elements and breakage. Transport of bone can produce breakage and can affect bone survivability. However, moschid bones do not show rounding due to abrasion - this erosion differs from digestion rounding in that the damage is not localized in certain areas but evenly spread over the whole surfaces of the bone (Andrews 1990; Fernández-Jalvo \& Andrews 1992) - and, although there exist a considerable bone loss overall, this cannot be attributed to transport because the assemblage records the coexistence of easily transportable elements (rod and sphere-shaped bones) and less likely to move elements (blade and disc-shaped bones) (Table 3). Accordingly, a long transport process can be rejected for the moschid assemblage.

Lithostatic pressure constitutes another process that can bring about breakage and destruction of bones. The presence of plastic deformation in some bones from the Batallones-1 LLA, the collapse of some remains and the existence of smooth perpendicular breaks in the long bones imply that these elements have undergone some sediment compaction (Domingo 2009). However, even though the amount of breakage due to this process can be considered as moderately high in the Batallones-1 LLA, bone destruction caused by lithostatic pressure must be considered as low as it is evidenced by the high survivorship of very delicate elements such as fibulae, scapulae, vertebrae and skulls (both of large and small mammals, reptiles, birds, lissamphibians and teleosteans). As for the moschid remains, most of them show a low incidence of sediment compaction alterations compared to the rest of the assemblage (Table 3). Besides, as previously mentioned and contrary to what is observed in the rest of Batallones-1 LLA, most of the Moschidae broken long bones exhibit spiral fractures (Tables 2 and 3 ). These fractures are believed to result from the breakage of fresh, green bone (Lyman 1994; and references therein) and this is coherent with a predation/scavenging process. Although some of the moschid broken long bones exhibit a transverse fracture (which is commonly attributed to the sediment overburden weight), they lack one of their ends (Fig. 5). Typically, long bones fractured due to lithostatic pressure preserve their conjoining fragments lying adjacent to, or in contact with, one another (Lyman 1994) and, in fact, this is the pattern observed in most of the transversally fractured long bones from Batallones-1 LLA (Fig. 7). Then, the absence of the 
moschid long bone edges in the fossil site rule out the attribution of transversally broken moschid bones to post-burial processes.

To sum up, all the taphonomic factors discussed can be discarded as responsible for the moschid bone loss and breakage and, thus, the predator activity that gave rise to the presence of modifications due to digestion in the musk deer accumulation is also considered to be the most feasible process to explain these patterns.

\section{Implications on the accumulation mode of the moschid assemblage}

The lower level of Batallones-1 fossil site can be considered as the bottom part of a cavity with an upper entrance, where many of the carnivoran individuals got trapped. The scenario where the moschids either got trapped or died in the fall and were subsequently attacked or consumed by a predator inside the cavity must, thus, be examined. In the context of a predator/scavenger-produced assemblage, skeletal part underrepresentation can be caused by the non-preservation of elements due to complete digestion, the excessive breakage which makes the elements unidentifiable or the rejection of these parts during feeding. The possibility that some remains could have suffered a complete digestion cannot be discarded, but it is highly unlikely that this process gave rise to the complete destruction of such a great amount of elements in all the moschid species with the total loss of the bones from the axial skeleton and most of the cranial elements for all the represented individuals.

In our taphonomic study, all the recovered splinters were evaluated. As previously indicated, only four splinters furnished unequivocal evidence of having passed through the digestive tract of a predator. Even assuming a possible underestimation on the number of digested splinters in Batallones-1 LLA, their proportion in the fossil site (splinters account for less than $4 \%$ of the total assemblage) and their large sizes in some cases (those splinters cannot come from musk deer elements) make it improbable that an extreme breakage produced by the predator/scavenger could be the cause of the high and selective bone underrepresentation in the moschid association.

As for a selective feeding behaviour of the responsible predator/s in the restricted area of the cavity where most of the individuals, including the predators, got trapped, this process would have given as a result a consumed moschid assemblage and a discarded moschid assemblage, that is, a more complete assemblage than the one found in Batallones-1 LLA. Even assuming that some of the predators could have made their way out the cavity, it is unlikely they took with them

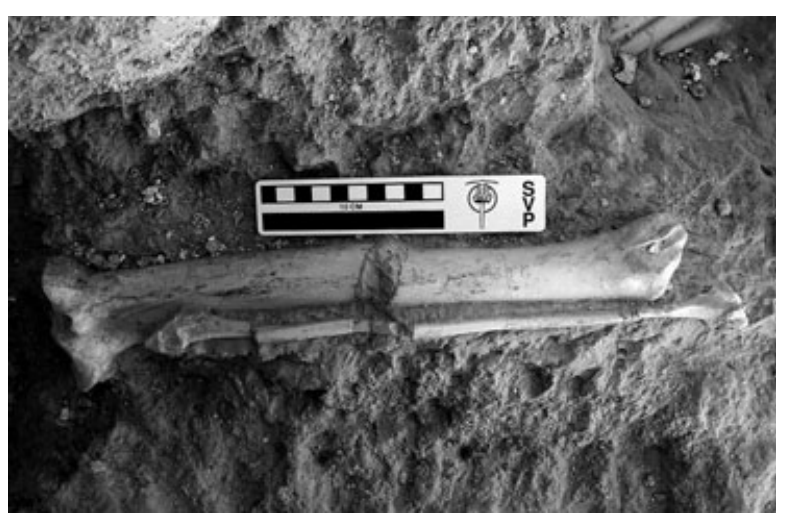

Fig. 7. Tibia and fibula of Machairodus aphanistus from Batallones-1 LLA displaying typical transverse fractures produced by lithostatic pressure. Note that all the fragments are preserved adjacent to one another.

all the axial and most of the cranial elements. Besides, the very low amount of fossils recovered in the last field season Batallones-1 LLA was excavated (summer 2008) indicated that the locality is practically exhausted at least in the excavated area so it is improbable that all of the missing moschid elements could have remained unearthed.

Given all these considerations, a more feasible scenario to explain the scarcity of moschid remains in Batallones-1 LLA is the one that considers that the moschids did not fall or get trapped but that the predator/scavenger's attack/consumption took place out of the cavity where there was a selection on the consumed and swallowed parts of the prey. Then, the predator/scavenger entered into the cavity and got trapped with some of the moschid remains in the digestive tract. The possibility that some of the moschid bones (e.g. bones without evident modifications due to digestion) could have been carried by the predator to the cave but not consumed and digested cannot be discarded. Whether the digested bones were deposited as regurgitations, defecations or stomach contents remains unknown. No coprolites or pellets have been found in Batallones-1 LLA but the inferred presence of shallow water bodies (Pozo et al. 2004) could have hindered their preservation. All these deposition modes would imply the presence of groupings of moschid remains; however, these fossils were found scattered in the excavation area (Fig. 8). The dispersion of the remains hampers the possibility of establishing a relationship between moschids and their predator/scavenger based on the spatial distribution of the fossils. Although extensive transport was precluded as an important process affecting this association, the dispersal of the moschid bones is indicative of at least a small amount of transport - inside the cavity - for them. Considering that the cavity filled as a result of successive clastic material contributions 
probably due to episodic floods (Pozo et al. 2004), a short distance transport inside the cave is reasonable.

Another line of evidence of an exterior hunting/scavenging and posterior incorporation of the moschid remains to the cavity by the predator or scavenger is the already pinpointed absence of one of the ends of most of the long bones. Again, if the predator/scavenger had subdued and consumed a moschid trapped in the cave it would be expectable to find in such a restricted area some of these long bone missing ends.

\section{Potential predators/scavengers on moschids from Batallones-1 LLA}

The recognition of the responsible predator/s or scavenger/s of the moschid assemblage from Batallones-1 LLA is not a straightforward task. The first difficulty comes from the small sample sizes of the three studied species, which make it not possible to establish statistically conclusive comparisons of their skeletal part representation with assemblages produced by known predators. Besides, as it was previously mentioned, most of the actualistic studies on scatological concentrations focus on small mammal remains. Differences in body size and bone fragility constitute a pitfall in comparing our ruminant sample with the small mammal concentrations reported in these studies. Furthermore, the actualistic studies are particularly useful when working with relatively modern accumulations where many of the modern predator and scavenger taxa are already present. Batallones- 1 fauna dates from around $9 \mathrm{Ma}$ so some of the potential predators do not have modern analogous as to establish an exact comparison. Many of the modern carnivoran families are already present at this time period; however, as it will be described later, the behaviour and adaptations of the Miocene species are not necessarily similar to those shown by their modern relatives.

We can try to elucidate some potential candidates for the moschid accumulation from the varied array of predators/scavengers discovered in Batallones- 1 . The presence of a predator species in a fossil assemblage is no proof that it was responsible for accumulating all or part of the remains there present (Andrews 1990). Nevertheless, the particular characteristics of Batallones- 1 fossil site that acted as a carnivore trap, make it viable to consider some of the predators there identified as probably responsible for the moschid assemblage.

The main predators of the extant moschids are mammalian carnivores such as the common wolf (Canis lupus), the fox (Vulpes vulpes), the lynx (Lynx lynx), the tiger (Panthera tigris), the leopard (Panthera pardus orientalis), the yellow-throated marten (Martes

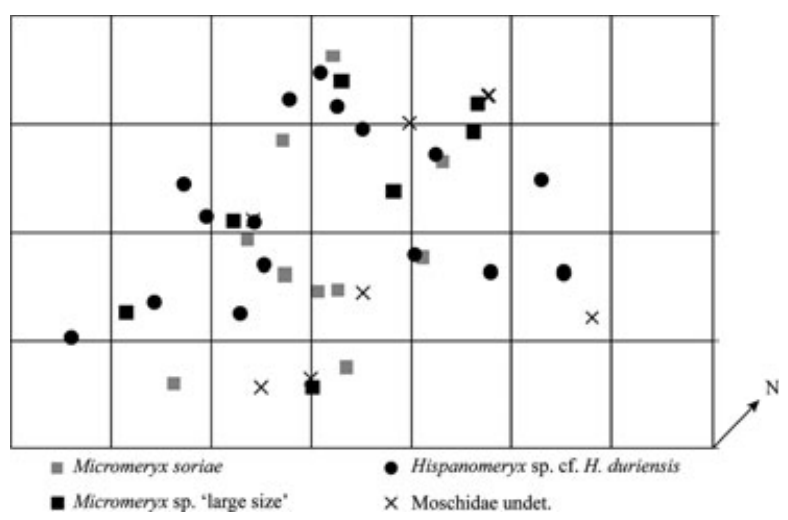

Fig. 8. Spatial distribution of musk deer remains in Batallones-1 fossil site area. Each point represents a bone. Individual grids have an area of $2 \mathrm{~m} \times 2 \mathrm{~m}$.

flavigula), the wolverine (Gulo gulo), and the sable (Martes zibellina) (Homes 2004). Although a direct reference to bird of prey attacks or scavenging on moschids was not found in the literature, numerous studies report the existence of small- and mediumsized ungulates on pellets and nests of raptors. For example, Trapani et al. (2006) found bones of duiker (Cephalophus monticola) in assemblages produced by crowned hawk-eagles (Stephanoaetus coronatus). The four vultures that today inhabit the Iberian Peninsula, the Egyptian vulture (Neophron pernocterus), the griffon vulture (Gyps fulvus), the cinereous vulture (Aegypius monachus), and the bearded vulture (Gypaetus barbatus), are able to swallow small- and medium-sized ungulates' bones (Robert \& Vigne 2002; Margalida 2008; Del Moral \& de la Puente 2010; Donázar et al. 2010). The bird assemblage from Batallones-1 is still under study; however, two vulture taxa have been recognized (A. Sánchez-Marco personal communication, 2010).

The mammalian carnivore taxa recovered from Batallones-1 LLA include two machairodontines (Machairodus aphanistus and Promegantereon ogygia), two felines whose taxonomy has still not been determined, an amphicyonid (Magericyon anceps), a hyaenid (Protictitherium crassum), an ailurid (Simocyon batalleri), a mustelid (Martes sp.), and two mephitids (Proputorius sp. and Sabadellictis sp.). Mammalian carnivores use their teeth to break up prey carcass before ingestion and digestion so that a high breakage percentage of the bones that are larger, such as what it has been determined for the moschid long bones, is expectable in assemblages produced by them. Nonetheless, some vultures (such as the bearded vulture) break bones by throwing the remains from the air onto rocky surfaces before ingesting them (Margalida \& Bertran 2001) so a high degree of fragmentation would also be common for such kind of raptors. Andrews (1990) highlighted that one of the most 
distinctive aspects of the bone assemblages produced by mammalian predators is the extent to which postcranial bones - and particularly broken edges - are rounded by the digestive processes. Robert \& Vigne (2002), in their study of assemblages produced by bearded vultures, also mentioned some degree of rounding in the bone edges. However, the photographs supplied by Andrews (1990, fig. 3.28) and Robert \& Vigne (2002, figs 3, 6) evidence a high degree of rounding and smoothing in bones broken by mammalian carnivores whereas broken bones from the bearded vulture assemblages exhibit a denticulate aspect where polishing is less evident. In this aspect, the sample described in this study better correlates with the mammalian carnivore pattern (Figs 5,6).

Given these considerations, the role that each mammalian carnivore could have played on the accumulation of the moschid remains can be evaluated. Works regarding the anatomy and functional morphology of the two machairodotines present in Batallones- 1 have allowed inferring different aspects of their ecology and behaviour (Antón et al. 2004a,b; Salesa et al. 2005, 2006a). Their sizes together with the special adaptations of their bite exclude them from being probable predators of such small prey as moschids. As indicated by Salesa et al. (2006a), sabre-toothed cats might have minimized the risk of breaking their upper canines by ignoring prey below a given size.

Two other felids belonging to the Felinae subfamily have been found in Batallones-1. One of them exhibits a size similar to a wildcat, whereas the other one shows a size comparable to a caracal. Wildcats mainly consume rodents and other small mammals but also birds, reptiles and insects (Nowak 1999). The diet of caracals is made up of micromammals, birds and reptiles and larger prey such as small antelopes (Nowak 1999). It is difficult to infer the behaviour and food preferences of the extinct felines from Batallones-1, although it is probable that the caracal-sized species could prey on moschids. Nevertheless, the study of the scats from feral cats and margays led Andrews \& Evans (1983) to conclude that digestion caused by felines was extreme as the remains were reduced to tiny flakes and fragments of jaw and both bones and teeth were severely corroded. The caracal scat studied by Matthews (2002) was composed of unidentifiable bones so an extreme degree of digestion can also be assigned to this feline. Therefore, regarding the high level of damage commonly caused by felines to the bones they ingest, it seems improbable that the two feline species from Batallones- 1 were the responsible for the digested moschid accumulation.

Mustelid remains from Batallones-1 are still under study, although one form - Martes sp. - seems to be related to the martens. Some studies have reported chases or hunts on musk deer by the yellow-throated marten (Parr \& Duckworth 2007; Abramov et al. 2008; and references therein); however, the literature does not determine whether the bones of the moschids are eaten and swallowed by this mustelid. As previously indicated, Homes (2004) also points to another marten, the sable, as a known predator of moschids but, again, the ecological studies are not specific about its capacity to swallow bones of smallsized ungulates. The marten from Batallones- 1 has a size more similar to the sable or the pine marten (Martes martes) than to the larger yellow-throated marten. The size of prey utilized by the pine marten varies from $3 \mathrm{~g}$ to $4 \mathrm{~kg}$ (Zalewski 2005). Extrapolating these data to the Martes from Batallones-1, the three musk deer species exhibit a larger body size than the reported range, although Micromeryx soriae and Hispanomeryx sp. cf. $H$. duriensis only slightly exceed the upper limit. Maybe young moschids would have also been a feasible prey for this mustelid. One of the Micromeryx soriae individuals is a juvenile. However, Andrews \& Evans (1983) indicate that only small mammals up to the size of a mouse or vole are well represented in the $M$. martes scats, whereas larger prey bone are scarce. Then, even though the Martes from Batallones-1 cannot be discarded as a possible predator of young moschids (or even adult Micromeryx soriae or Hispanomeryx sp. cf. H. duriensis), its small size dismisses it as responsible for the accumulation of the partially digested moschid assemblage from Batallones-1 LLA.

The remains of two mephitids - Sabadellictis sp. and Proputorius sp. - that seem to be related to the skunks have been found in Batallones-1. Studies on different modern skunk species indicate that invertebrates compose the bulk of their diet but sometimes consume vertebrates such as small mammals, birds, reptiles and carrion (Larivière \& Messier 2000; Widmann \& Widmann 2004; Montalvo et al. 2008; Dragoo \& Sheffield 2009). In the taphonomic study of the scats of the Andean hog-nosed skunk (Conepatus chinga) carried out by Montalvo et al. (2008), the only mammals that could be identified on the basis of the bone material they contained were rodents with body sizes ranging from 20 to $250 \mathrm{~g}$. The bone assemblage exhibited a high degree of breakage with higher destruction of bone as the size of the prey increased. The skunks from Batallones-1 are smaller than the Andean hog-nosed skunk so it would be expectable that they fed on even smaller preys and bones. Then, in the light of the diet preferences of the skunks, the degree of fragmentation of bone in their faeces and the small size of the skunks from Batallones-1, it is unlikely that either of these two mephitids preyed on moschids or consumed their bones. 
The study of the dentition of the ailurid S. batalleri, which is related to Ailurus fulgens, the red panda, indicates that, the diet of this extinct species was based on flesh and carrion (Peigné et al. 2005; Salesa et al. 2006b). Peigné et al. (2005) determined that Simocyon dentition exhibits some characteristics comparable to those furnished by the later member of the canid subfamily Borophaginae although in Simocyon the crushing function of the teeth was less developed. So even though it has been inferred that this puma-sized taxon would have had bone-crushing abilities it would not have occupied a strictly bone crushing niche; rather this adaptation for cracking bone could be related to a full utilization of prey which could have been eaten complete including the bones (Peigné et al. 2005; Salesa et al. 2008). These inferences concerning its feeding behaviour lead us to consider S. batalleri as a feasible candidate for the consumption and accumulation of the moschid remains.

Magericyon anceps was a lioness-sized carnivoran that belonged to the extinct family Amphicyonidae. Amphicyonids possess dentitions adapted to a carnivorous diet albeit their strong post-carnassial teeth point to bone-crushing capabilities as well. In the particular case of Magericyon anceps, Peigné et al. (2008) pinpointed that the crushing function was of lesser importance in this taxon than in other amphicyonids, that is, Magericyon anceps shows hypercarnivorous traits in its dentition that imply a great consumption of meat. Magericyon anceps dentition displays another characteristic feature, which is the presence of strongly flattened upper canines. This compression would increase the risk of fracture due to lateral forces so Peigné et al. (2008) proposed that Magericyon anceps would have been more likely to avoid a teeth-bone contact. This particular dental trait could have prevented this taxon from subduing ungulates as small as moschids. However, it must not be discarded the possibility that the moschid remains could have been consumed by these amphicyonids not as prey but as carrion.

Protictitherium crassum was a primitive hyaenid, which exhibited a size comparable to the extant African civet, Civettictis civetta (Antón \& Morales 2000). This hyaenid does not sport a dentition adapted to crack bone so it has been inferred that it could have been an opportunistic carnivoran with a diet and behaviour more similar to a jackal than to a modern hyaena (Antón \& Morales 2000; Salesa et al. 2006b). In fact, Agustí \& Antón (2002) suggested that Protictitherium diet would be composed of micromammals, birds and insects. Accordingly, the limited capacity of $P$. crassum as a bone crusher and eater leads us to consider it as an improbable responsible for the moschid concentration.
The possibility that a predator not represented in the fossil assemblage of Batallones-1 (i.e. it could made its way out of the cavity after depositing the moschid remains) could have contributed to the concentration of the moschid bone assemblage cannot be completely dismissed. Finally, it must be highlighted that the examination of the small mammal (and other vertebrates) remains is needed so that we can gain a more complete overview of the presence of modifications due to digestion in Batallones-1.

\section{Conclusions}

Detailed taphonomic examination of the remains from the Late Miocene site of Batallones-1 (LLA) allowed the detection of fossil bones showing modifications typical of a digestion process. Most of the digested bones belong exclusively to members of the family Moschidae. The three represented moschid species display low bone survivability and extreme breakage of their long bones (62.5\% of them showing spiral fractures) that can also be attributable to a predatory/scavenging process. The significant absence of some portions (the axial and cranial elements), and most of one of the edges of the broken long bones in the assemblage is indicative of a predator/scavenger activity that took place out of the cavity. The moschid remains were then incorporated into the assemblage as stomach contents - when the predator/scavenger became trapped in the cave.

Considering the distinctive features exhibited by the Moschidae remains and the varied array of carnivores present in Batallones-1, some potential candidate/s for the production of this assemblage have been proposed. S. batalleri dental specializations make of this ailurid the most feasible taxa for preying and/or scavenging on moschid remains. Magericyon anceps could have also brought bones into the cavity after scavenging on moschid carcasses. Although, the two vultures present in the assemblage would have had the capacity of consuming and swallowing moschid remains, the type of alterations present in the digested bones better adapts to those described for mammalian carnivores.

The fact that the digested remains were of mammalian taxa different to small mammals constitutes an important contribution to our knowledge of the fossil record of accumulations originated by the ingestion and digestion of bones. The moschid bone features described in this study constitute a testimony of ancient predator-prey interactions in a Miocene ecosystem.

Acknowledgements. - We thank Drs Yolanda Fernández-Jalvo and M. Dolores Pesquero for their help in the early stages of this study. We are also grateful to Marta Furió, Alberto Jorge and Laura 
Tormo for their excellent assistance during the ESEM sessions (Museo Nacional de Ciencias Naturales-CSIC, Madrid, Spain). Comments provided by Laura Domingo and Catherine Badgley improved the manuscript. Mauricio Antón graciously gave permission for us to use his illustration of Micromeryx. We thank Lethaia Editor Peter Doyle, Dr Yolanda Fernández-Jalvo and an anonymous reviewer for helpful comments. This study was funded by the Spanish Government Ministry of Science and Innovation research projects CGL2008-05813-C02-01/BTE, CGL200760790/BTE, and CGL2010-19116/BOS and is included in the CAM-UCM 910607 Research Group. MSD was supported by the Fundación Española para la Ciencia y la Tecnología (FECYT) and the Spanish Ministry of Education postdoctoral fellowship programme. IMS acknowledges a CSIC JAE-Doc contract from the programme Junta para la Ampliación de Estudios, co-funded by the European Social Fund.

\section{References}

Abramov, A., Timmins, R.J., Roberton, S., Long, B., Than Zaw \& Duckworth, J.W. 2008: Martes flavigula. In IUCN Red List of Threatened Species. Version 2010.4. <http://www.iucnredlist. org $>$. Accessed on 15 December 2010.

Agustí, J. \& Antón, M. 2002: Mammoths, Sabertooths and Hominids. 65 Million Years of Mammalian Evolution in Europe, 313 pp. Columbia University Press, New York.

Andrews, P. 1990: Owls, Caves and Fossils, 239 pp. The University of Chicago Press, Chicago and London.

Andrews, P. \& Ersoy, A. 1990: Taphonomy of the Miocene bone accumulations at Paşalar, Turkey. Journal of Human Evolution 19, 379-396.

Andrews, P. \& Evans, E.M.N. 1983: Small mammal bone accumulations produced by mammalian carnivores. Paleobiology 9, 289307.

Antón, M. \& Morales, J. 2000: Inferencias paleoecológicas de la asociación de carnívoros del yacimiento de Cerro Batallones. In Morales, J. (ed.): Patrimonio Paleontológico de la Comunidad de Madrid. Arqueología, Paleontología \& Etnografía, monográfico 6, 190-201. Serie de la Consejería de Educación Comunidad de Madrid, Madrid.

Antón, M., Salesa, M.J., Morales, J. \& Turner, A. 2004a: First known complete skulls of the scimitar-toothed cat Machairodus aphanistus (Felidae, Carnivora) from the Spanish Late Miocene site of Batallones-1. Journal of Vertebrate Paleontology 24, 957969.

Antón, M., Salesa, M.J., Pastor, J.F., Sánchez, I.M., Fraile, S. \& Morales, J. 2004b: Implications of the mastoid anatomy of larger extant felids for the evolution and predatory behaviour of sabretoothed cats (Mammalia, Carnivora, Felidae). Zoological Journal of the Linnean Society 140, 207-221.

Badgley, C. 1986: Counting individuals in mammalian fossil assemblages from fluvial environments. Palaios 1, 328-338.

Behrensmeyer, A.K. 1978: Taphonomic and ecologic information from bone weathering. Paleobiology 4, 150-162.

Cerdeño, E. \& Sánchez, B. 1998: Aceratherium incisivum (Rhinocerotidae) en el Mioceno Superior de Cerro de los Batallones (Madrid). Revista Española de Paleontología 13, 51-60.

Crandall, B.D. \& Stahl, P.W. 1995: Human digestive effects on a micromammalian skeleton. Journal of Archaeological Science 22, 789-797.

Del Moral, J.C. \& de la Puente, J. 2010: Buitre negro-Aegypius monachus (Linnaeus, 1766). In Salvador, A. \& Bautista, L.M. (eds): Enciclopedia virtual de los vertebrados españoles. Museo Nacional de Ciencias Naturales-CSIC, Madrid. http://www.vertebradosibericos.org/. Accessed on 3 December 2010.

Dodson, P. \& Wexlar, D. 1979: Taphonomic investigations of owl pellets. Paleobiology 5, 275-284.

Domingo, M.S. 2009: Estudio tafonómico del yacimiento de vertebrados vallesienses (Mioceno Superior) de Batallones 1, Torrejón de Velasco, Madrid, 507 pp. Unpublished $\mathrm{PhD}$ dissertation, Universidad Complutense de Madrid, Madrid.
Domingo, M.S., Sánchez, I.M., Morales, J. \& Alberdi, M.T. 2007: Miocene prey and predators: diversity of the Moschidae (Ruminantia; Pecora) from the carnivore-trap site of Batallones-1 (Late Vallesian; MN10; Madrid Basin; Spain) and evidence of carnivore trophic activity on moschids. Journal of Vertebrate Paleontology 27, 69A.

Domingo, M.S., Domingo, L., Sánchez, I.M., Alberdi, M.T., Azanza, B. \& Morales, J. 2011: New insights on the taphonomy of the exceptional mammalian fossil sites of Cerro de los Batallones (Late Miocene, Spain) based on Rare Earth Element geochemistry. Palaios 26, 55-65.

Donázar, J.A., Cortés-Avizanda, A. \& Carrete, M. 2010: Dietary shifts in two vultures alter the demise of supplementary feeding stations: consequences of the EU sanitary legislation. European Journal of Wildlife Research 56, 613-621.

Dragoo, J.W. \& Sheffield, S.R. 2009: Conepatus leuconotus (Carnivora, Mephitidae). Mammalian Species 827, 1-8.

Esteban-Nadal, M., Cáceres, I. \& Fosse, P. 2010: Characterization of a current coprogenic sample originated by Canis lupus as a tool for identifying a taphonomic agent. Journal of Archaeological Science 37, 2959-2970.

Farlow, J.O., Chin, K., Argast, A. \& Poppy, S. 2010: Coprolites from the Pipe Creek Sinkhole (Late Neogene, Grant County, Indiana, USA). Journal of Vertebrate Paleontology 30, 959-969.

Fernández-Jalvo, Y. \& Andrews, P. 1992: Small mammal taphonomy of Gran Dolina, Atapuerca (Burgos), Spain. Journal of Archaeological Science 19, 407-428.

Fernández-Jalvo, Y., Denys, C., Andrews, P., Williams, T., Dauphin, Y. \& Humphrey, L. 1998: Taphonomy and paleoecology of Olduvai Bed-I (Pleistocene, Tanzania). Journal of Human Evolution 34, 137-172.

Fisher, D.C. 1981: Crocodilian scatology, microvertebrate concentrations, and enamel-less teeth. Paleobiology 7, 262-275.

Frostick, L. \& Reid, I. 1983: Taphonomic significance of sub-aerial transport of vertebrate fossils on steep semi-arid slopes. Lethaia $16,157-164$.

Hockett, B.C. 1996: Corroded, thinned and polished bones created by golden eagles (Aquila chrysaetos): taphonomic implications for archaeological interpretations. Journal of Archaeological Science 23, 587-591.

Homes, V. 2004: No Licence to Kill: The Population and Harvest of Musk Deer and Trade in Musk in the Russian Federation and Mongolia, 100 pp. Traffic Europe, Brussels.

Larivière, S. \& Messier, F. 2000: Habitat selection and use of edges by striped skunks in the Canadian prairies. Canadian Journal of Zoology 78, 366-372.

Laudet, F. \& Selva, N. 2005: Ravens as small mammal bone accumulators: first taphonomic study on mammal remains in raven pellets. Palaeogeography, Palaeoclimatology, Palaeoecology 226, 272-286.

Lloveras, L., Moreno-García, M. \& Nadal, J. 2008: Taphonomic study of leporid remains accumulated by the Spanish Imperial Eagle (Aquila adalberti). Geobios 41, 91-100.

López-Antoñanzas, R., Peláez-Campomanes, P., Álvarez-Sierra, M.A. \& García Paredes, I. 2010: New species of Hispanomys (Rodentia, Cricetodontinae) from the Upper Miocene of Batallones (Madrid, Spain). Zoological Journal of the Linnean Society 160, 725-747.

Lyman, R.L. 1994: Vertebrate Taphonomy, 524 pp. Cambridge University Press, Cambridge.

Margalida, A. 2008: Bearded vultures (Gypaetus barbatus) prefer fatty bones. Behavioral Ecology and Sociobiology 63, 187-193.

Margalida, A. \& Bertran, J. 2001: Function and temporal variation in the use of ossuaries by the Bearded Vulture (Gypaetus barbatus) during the nestling period. Auk 118, 785-789.

Marín Arroyo, A.B., Fosse, P. \& Vigne, J.-D. 2009: Probable evidences of bone accumulation by Pleistocene bearded vulture at the archaeological site of El Mirón Cave (Spain). Journal of Archaeological Science 36, 284-296.

Matthews, T. 2002: South African micromammals and predators: some comparative results. Archaeometry 44, 363-370.

Mellet, J.S. 1974: Scatological origin of microvertebrate fossil accumulations. Science 185, 349-350. 
Montalvo, C.I., Pessino, M.E.M. \& González, V.H. 2007: Taphonomic analysis of remains of mammals eaten by pumas (Puma concolor Carnivora, Felidae) in central Argentina. Journal of Archaeological Science 34, 2151-2160.

Montalvo, C.I., Pessino, M.E.M. \& Bagatto, F.C. 2008: Taphonomy of the bone of rodents consumed by Andean hog-nosed skunks (Conepatus chinga, Carnivora, Mephitidae) in central Argentina. Journal of Archaeological Science 35, 1481-1488.

Morales, J., Capitán, J., Calvo, J.P. \& Sesé, C. 1992: Nuevo yacimiento de vertebrados del Mioceno Superior al sur de Madrid (Cerro Batallones, Torrejón de Velasco). Geogaceta 12, 77-80.

Morales, J., Pozo, M., Silva, P.G. et al. 2008: El sistema de yacimientos de mamíferos miocenos del Cerro de los Batallones, Cuenca de Madrid: estado actual y perspectivas. Paleontologica Nova SEPAZ 8, 41-117.

Nowak, R.M. 1999: Walker's Mammals of the World. Sixth Edition. Volume II, 1921 pp. The Johns Hopkins University Press, Baltimore and London.

Parr, J.W.K. \& Duckworth, J.W. 2007: Notes on the diet, habituation and sociality of Yellow-throated Marten Martes flavigula. Small Carnivore Conservation 36, 27-29.

Peigné, S., Salesa, M.J., Antón, M. \& Morales, J. 2005: Ailurid carnivoran mammal Simocyon from the Late Miocene of Spain and the systematics of the genus. Acta Paleontologica Polonica 50, 219-238.

Peigné, S., Salesa, M.J., Antón, M. \& Morales, J. 2008: A new Amphicyonine (Carnivora: Amphicyonidae) from the Upper Miocene of Batallones-1, Madrid, Spain. Palaeontology 51, 943 965.

Pickering, T.R. \& Carlson, K.J. 2004: Baboon taphonomy and its relevance to the investigation of large felid involvement in human forensic cases. Forensic Science International 144, 37-44.

Pozo, M., Calvo, J.P., Silva, P.G., Morales, J., Peláez-Campomanes, P. \& Nieto, M. 2004: Geología del sistema de yacimientos de mamíferos miocenos del Cerro de los Batallones, Cuenca de Madrid. Geogaceta 35, 143-146.

Prikhodko, V.I. 2003: Musk Deer, 443 pp. GEOS, Moscow. [In Russian]

Robert, I. \& Vigne, J.-D. 2002: The Bearded Vulture (Gypaetus barbatus) as an accumulator of archaeological bones. Late glacial assemblages and present-day reference data in Corsica (Western Mediterranean). Journal of Archaeological Science 29, 763-777.

Salesa, M.J., Antón, M., Turner, A. \& Morales, J. 2005: Aspects of the functional morphology in the cranial and cervical skeleton of the sabre-toothed cat Paramachairodus ogygia (Kaup, 1832) (Felidae, Machairodontinae) from the Late Miocene of Spain: implications for the origins of the machairodont killing bite. Zoological Journal of the Linnean Society 144, 363377.

Salesa, M.J., Antón, M., Turner, A. \& Morales, J. 2006a: Inferred behaviour and ecology of the primitive sabre-toothed cat Paramachairodus ogygia (Felidae, Machairodontinae) from the late Miocene from Spain. Journal of Zoology 268, 243254.

Salesa, M.J., Antón, M., Peigné, S. \& Morales, J. 2006b: Evidence of a false thumb in a fossil carnivore clarifies the evolution of pandas. Proceedings of the National Academy of Sciences 103, 379-382.

Salesa, M.J., Antón, M., Peigné, S. \& Morales, J. 2008: Functional anatomy and biomechanics of the postcranial skeleton of Simocyon batalleri (Viret, 1929) (Carnivora, Ailuridae) from the late
Miocene of Spain. Zoological Journal of the Linnean Society 152, 593-621.

Salesa, M.J., Antón, M., Turner, A. \& Morales, J. 2009: Functional anatomy of the forelimb in Promegantereon ogygia (Felidae, Machairodontinae, Smilodontini) from the Late Miocene of Spain and the origins of the sabre-toothed felid model. Journal of Anatomy 216, 381-396.

Sánchez, I.M. 2006: Evolución y sistemática de los Moschidae (Mammalia; Artiodactyla) del Mioceno medio y superior de España, 513 pp. Unpublished $\mathrm{PhD}$ dissertation, Universidad Complutense de Madrid, Madrid.

Sánchez, I.M. \& Morales, J. 2006: Distribución biocronológica de los Moschidae (Mammalia, Ruminantia) en España. Estudios Geológicos 62, 533-546.

Sánchez, I.M. \& Morales, J. 2008: Micromeryx azanzae sp. nov. (Ruminantia: Moschidae) from the Middle-Upper Miocene of Spain, and the first description of the cranium of Micromeryx. Journal of Vertebrate Paleontology 28, 873-885.

Sánchez, I.M., Domingo, M.S. \& Morales, J. 2009: New data on the Moschidae (Mammalia, Ruminantia) from the Upper Miocene of Spain (MN10-MN11). Journal of Vertebrate Paleontology 29, 567-575.

Sánchez, I.M., Domingo, M.S. \& Morales, J. 2010: The genus Hispanomeryx (Mammalia, Ruminantia, Moschidae) and its bearing on musk deer phylogeny and systematics. Paleontology 53, 10231047.

Sanz, J.L., Chiappe, L.M., Fernández-Jalvo, Y., Ortega, F., SánchezChillón, B., Poyato-Ariza, F.J. \& Pérez-Moreno, B.P. 2001: An Early Cretaceous pellet. Nature 409, 998-999.

Schmitt, D.N. \& Juell, K.E. 1994: Toward the identification of coyote scatological faunal accumulations in archaeological contexts. Journal of Archaeological Science 21, 249-262.

Shipman, P. 1981: Life History of a Fossil. An Introduction to Taphonomy and Paleoecology, 222 pp. Harvard University Press, Cambridge and London.

Stewart, K.M., Leblanc, L., Matthiesen, D.P. \& West, J. 1999: Microfaunal remains from a modern East African raptor roost: patterning and implications for fossil bone scatters. Paleobiology 25, 483-503.

Sutcliffe, A.J. 1970: Spotted hyena: crusher, gnawer, digester and collector of bones. Nature 227, 1110-1113.

Tappen, M. \& Wrangham, R. 2000: Recognizing hominoid-modified bones: the taphonomy of colobus bones partially digested by free-ranging chimpanzees in the Kibale Forest, Uganda. American Journal of Physical Anthropology 113, 217-234.

Trapani, J., Sanders, W.J., Mitani, J.C. \& Heard, A. 2006: Precision and consistency of the taphonomic signature of predation by Crowned Hawk-Eagles (Stephanoaetus coronatus) in Kibale National Park, Uganda. Palaios 21, 114-131.

Varricchio, D.J. 2001: Gut contents for a Cretaceous tyrannosaur: implications for theropod dinosaur digestive tracts. Journal of Paleontology 75, 401-406.

Vislobokova, I.A. 2007: New data on Late Miocene mammals of Kohfidisch, Austria. Paleontological Journal 41, 451-460.

Widmann, P. \& Widmann, I. 2004: Ecology and conservation of the Palawan Stink Badger Mydaus marchei Huet, 1887. Small Carnivore Conservation 30, 16-17.

Zalewski, A. 2005: Geographical and seasonal variation in food habits and prey size of European Pine Martens. In Harrison, D.J., Fuller, A.K. \& Proulx, G. (eds): Martens and Fishers (Martes) in Human-Altered Environments, 77-98. Springer, New York. 